\title{
THE INFLUENCE OF ALCOHOL RELATED ACCIDENTS ON HEALTH CARE COST
}

\author{
Bulut Demirel ${ }^{1}$, Mehmet Ergin², Ayhan Özhasenekler ${ }^{2}$, Cahit Teke², Fatih Tanrıverdi², \\ Gülhan Kurtoğlu Çelik ${ }^{2}$, Alp Şener ${ }^{1}$, Gül Pamukçu Günaydın, Şervan Gökhan ${ }^{2}$ \\ ${ }^{1}$ Ankara Atatürk Education and Research Hospital, Department of Emergency Medicine, Ankara, Turkey \\ ${ }^{2}$ Ankara Yıldırım Beyazıt University Atatürk Education and Research Hospital, Department of Emergency Medicine, Ankara, Turkey
}

\begin{abstract}
INTRODUCTION: Road traffic accidents are globally leading causes of mortality and morbidity. Alcohol is among the most frequently used pleasure-inducing substances in the world. Use of motor vehicle under the influence of alcohol is completely illegal in some countries. However, it is allowed up to a certain level of ethanol in blood in other countries. Traffic accidents caused by alcohol consumption are known to cause more harm on health of individuals. The alcohol affects nervous system. Alcohol slows reflexes and impairs balance. In other words, alcohol intake reduces capability of individuals while using any motor vehicle. This study aims to search the health care cost of individuals who had traffic accidents under the influence of alcohol.
\end{abstract}

METHODS: This present study included 657 patients who were admitted to the E.R. resulting from traffic accidents between the dates 01.01.2017-01.06.2017. Demographic information of the patients, their time of hospital admission, medical analyses and examinations, the cost of those analyses and examinations, and their ethanol levels were recorded.

RESULTS: 657 patients were included in the study. 460 (68.1) of those patients were males. Their age average was $35.57 \pm 15.18 .61(9.0 \%)$ of the patients were seen to have ethanol positive blood. The health care expenditures of ethanol positive patients were found to be $374,75 \pm 251,3 \mathrm{TL}$ whereas the expenditures of ethanol free patients were identified to be $283,17 \pm 222,72 \mathrm{TL}$. The health care expenditures of ethanol positive patients were seen to have substantially increased. $(p=0,003)$.

CONCLUSIONS: Alcohol intake is known to be a leading cause of traffic accidents that generally results in deaths and heavy injuries. This present study displays that traffic accidents caused by alcohol consumption increases the cost of health care as well.

KEY WORDS: alcohol, traffic, accident, health care, cost

\section{INTRODUCTION}

Traffic accidents are one of the biggest public health care problems in the world [1]. Every year, traffic accidents cause death of 1.24 million people. The number of injured people is approximately $40-50$ million. Traffic accidents account for the eighth cause of mortality of individuals aged between 15 and 29 [2]. The injuries caused by traffic accidents constitute a lifelong burden on the health care system [3]. Consumption of alcohol and psychoactive substances and non-use of protective equipment (head guard, seat belt etc.) are factors that increase fatal- 
ity of traffic accidents, duration of hospitalization and health care expenditures. Among the pleasure inducing substances, alcohol is the major cause of severe and fatal traffic accidents. Previous studies showed that blood alcohol level between $0.5 \mathrm{~g} / \mathrm{L}$ and $0.7 \mathrm{~g} / \mathrm{L}$ (a little more of legal limit in Turkey) caused traffic accidents more than 4-10 times. The same study displayed that blood alcohol level between $0.2 \mathrm{~g} / \mathrm{L}$ and $0.4 \mathrm{~g} / \mathrm{L}$ caused traffic accidents more than 2-5 times. It is obvious that even little changes of alcohol levels in blood cause traffic accidents at increasing levels $[4,5]$. For that reason, low alcohol level in blood is recommended [6].

According to the 2016 data, more than 1 million 182 thousand traffic accidents took place in Turkey. Although most of those accidents had financial loss, 7300 people lost their lives (3800 people died after hospitalization) and nearly 304000 people got injured [7]. However, the literature has the limited knowledge of accidents resulted from alcohol intake and the health care cost of those accidents. This present study aims to evaluate patients/injured people who were admitted to E.R. because of traffic accidents in terms of their ethanol levels, demographic features and cost on health care system. It is a fact that the risk of accident occurrence while using motor vehicle after alcohol consumption is much higher than usually. This condition is important not only for motor vehicle users, but also for those who use any vehicle in traffic. Alcohol related accidents have more severe and heavier results than accidents caused by other factors. For that reason, those accidents necessitate hospital interventions that will cover both trauma and the effects of alcohol on body. We investigated the effect of alcohol consumption on the health care cost.

\section{METHODS}

The study included over 18 patients after traffic accidents who were admitted to the E.R. of a tertiary healthcare service between the dates 01.01.2017-01.06.2017. Patients' blood ethanol level, demographic features, admission time and health care cost were recorded. The parameters were analyzed with SPSS for Windows 15.0 version. In descriptive statistics of continuous variables, average was stated with standard deviation; categorical variables were stated with numbers and percentages. For categorical variables, significance of difference between the groups was evaluated with Q-Square Test.
In the analysis of normally distributed parameters, parametric tests were used. Non-parametric tests were used in not normally distributed parameters. In comparison of binary groups, Mann Whitney $U$ test was used. $P<0.05$ value was accepted to be statistically significant.

\section{RESULTS}

657 patients were included in the study. 460 (68.1) of those patients were male. Their age average was $35.57 \pm 15.18 .61(9.0 \%)$ of the patients had ethanol positive blood. 47 (77.0\%) of the ethanol positive patients were male. $413(67.3 \%)$ of the ethanol free patients were male. Ethanol level status was similar in both genders $(p=0.118)$. Age range was also similar in both genders $(p=0,198)$. The health care cost of the ethanol positive patients was $374,75 \pm 251,3 \mathrm{TL}$ whereas the cost of ethanol free patients was $283,17 \pm 222,72 \mathrm{TL}$. The cost of ethanol positive patients was seen to increase substantially $(p=0,003)$. Table 1 shows patients' demographic parameters, admission time and health care cost.

Age groups of the patients are displayed in the Table 1 as well. The expenditures are seen to increase with age $(p<0,001)$. There was a weak positive correlation between the cost and the age $(p<0,001, r=0,163)$.

\section{DISCUSSION}

Global struggle of World Health Organization (WHO) with alcohol addiction has not been as successful as their struggle with tobacco. Both alcohol and tobacco consumptions are still global health problems [8]. According to the WHO data, alcohol is associated with homicide, violence, theft, rape and traffic accidents [9]. Use of motor vehicle under the influence of alcohol and other psychoactive substances is the most frequently seen human cause of traffic accidents [10]. Alcohol and psychoactive substances reduce capability of using any motor vehicle $[11,12]$. Although it is tried to be hindered with a certain legal limits, some problems associated with measurements and individual differences are confronted [13]. The use of alcohol with other addictive substances causes worse results [14]. Reduced capability of using a motor vehicle due to those substances and non-use of protective equipment result in traffic accidents with high mortality rates and heavy injuries [15-17]. 


\begin{tabular}{|c|c|c|c|c|}
\hline & All Patients & Ethanol $(+)$ & Ethanol (-) & $p$ \\
\hline Cost; avg. \pm s.d. & $291,45 \pm 226,78$ & $374,75 \pm 251,30$ & $283,17 \pm 222,72$ & 0,003 \\
\hline Age; avg. \pm s.d. & $35,57 \pm 15,18$ & $33,18 \pm 12,02$ & $33,18 \pm 12,02$ & 0,198 \\
\hline \multicolumn{4}{|l|}{ Age Groups; n (\%) } & \\
\hline 0-18 age & $25(\% 3,7)$ & - & $25(\% 4,1)$ & \\
\hline 19-25 age & $193(\% 28,5)$ & $21(\% 34,4)$ & $172(\% 28)$ & \\
\hline $26-45$ age & $306(\% 45,3)$ & $32(\% 52,5)$ & $274(\% 44,6)$ & \\
\hline $46-65$ age & $116(\% 17,1)$ & $6(\% 9,8)$ & $110(\% 17,9)$ & \\
\hline Over 65 & $35(\% 5,1)$ & $2(\% 3,3)$ & $33(\% 5,4)$ & \\
\hline Gender; n (\%) & & & & \multirow[t]{3}{*}{0,118} \\
\hline Female & $215(\% 31,8)$ & $14(\% 23)$ & $201(\% 32,7)$ & \\
\hline Male & $460(\% 68,1)$ & $47(\% 77)$ & $413(\% 67,3)$ & \\
\hline \multicolumn{4}{|l|}{ Admission time; n (\%) } & \\
\hline 00:00-07:59 & $202(\% 29,9)$ & $26(\% 42,6)$ & $176(\% 28,7)$ & \\
\hline 08:00-15:59 & $245(\% 36,2)$ & $15(\% 24,6)$ & $230(\% 37,5)$ & \\
\hline $16: 00-23: 59$ & $228(\% 33,7)$ & $20(\% 32,8)$ & $208(\% 33,9)$ & \\
\hline
\end{tabular}

The patient group that is most affected by traffic accidents is aged between 18 and 49 . The stated reason for this is that this age group is mostly unwilling to obey traffic rules, speed limits and other traffic regulations $[18,19]$. In the first decade of their lives, people live their fastest period. People whose age is between 20 and 40 tend to have more traffic accidents because of using motor vehicles more recklessly [20-22]. This present study includes 499 patients $(79,75 \%)$ aged between 18 and 45, which is compatible with the literature. Hospital admissions after traffic accidents show intensity between 00.00-08.00 hours, which results from alcohol consumption generally at night hours. The distribution of genders in traffic accidents caused by alcohol show similarity, which is opposite to the general idea that mostly males use alcohol and females use vehicles more carefully $[23,24]$. A study done on university students showed that alcohol consumption was frequent at night and disturbed sleep caused attention deficiency at chronic period, which is a cause of traffic accident [25]. This present study is compatible with this literature. The literature showed that alcohol related traffic accident victims cost more to the health care system when compared to the cost of the victims after non-alcohol related accidents [26]. This literature does not include traffic accidents of pedestrians and cyclists [27, 28]. Another study showed that in addition to financial burden of those alcohol caused traffic accidents to the health care system, those cases resulted in longer hospitalization periods at E.R. [29]. Our study also showed that alcohol related traffic accidents cost more to healthcare system. Nearly one-tenth of the patients were identified to have ethanol positive blood. Even if this rate seems to be low at first sight, a full-scale study which examined improper overtaking, exceeding the speed limits and sleeplessness showed that the use of motor vehicle after alcohol intake caused accidents with more fatality and heavy injuries and financial damage [30]. This decile rate had higher mortality and morbidity rates compared to the other reasons, which should be taken into consideration [25].

This present study is a pilot study that was done in a very short time, which can be counted as one of the limitations of our study. Additionally, the study does not include factors such as socio-economic status which affects health care cost and use of protection equipment during the accidents. Patients who lost their lives at the scene of the accidents also have a health care cost. However, this is a study that merely centered on emergency admissions.

Authors declare no conflict of interest. No funding was used by authors.

\section{CONCLUSIONS}

Among the pleasure-inducing substances, alcohol is the most frequently used one. Alcohol has a variety of consumption in various cultures. It is known to be a leading cause of traffic accidents. This present 
study showed that traffic accidents caused by alcohol had higher health care cost.

\section{REFERENCES}

1. Özen E, Genç E, Kaya Z. Awareness of Traffic Accidents and Thoughts on Traffic and Traffic: The Case of Uşak Province. 2014.

2. Peden $M$, Scurfield $R$, Sleet $D$, et al. World report on road traffic injury prevention. World Health Organization Geneva. 2004.

3. Murray $\mathrm{CJ}$, Lopez AD. Alternative projections of mortality and disability by cause 1990-2020: Global Burden of Disease Study. Lancet. 1997; 349(9064): 1498-1504, doi: 10.1016/50140-6736(96)07492-2, indexed in Pubmed: 9167458.

4. Heifer U. Blood alcohol concentration and effect, traffic medicine characteristics and legal traffic relevance of alcohol limit values in road traffic. Blutalkohol. 1991; 28(3): 121-145, indexed in Pubmed: 1867841.

5. Phillips DP, Brewer KM. The relationship between serious injury and blood alcohol concentration (BAC) in fatal motor vehicle accidents: $\mathrm{BAC}=0.01 \%$ is associated with significantly more dangerous accidents than $\mathrm{BAC}=0.00 \%$. Addiction. 2011; 106(9): 1614-1622, doi: 10.1111/j.1360-0443.2011.03472.x, indexed in Pubmed: 21689195.

6. Karakus A, idiz N, Dalgiç M, et al. Comparison of the effects of two legal blood alcohol limits: the presence of alcohol in traffic accidents according to category of driver in Izmir, Turkey. Traffic Inj Prev. 2015; 16(5): 440-442, doi: 10.1080/15389588.2014.968777, indexed in Pubmed: 25375366.

7. TÜiK. Turkey Statistic Institution, Road Traffic Accident Statistics. 2016, 2017.

8. Aydin $\mathrm{S}$. Global strategies in the struggle against alcohol from the WHO. Health and Medical Culture Journal. 2011(12).

9. Varol M. Alcohol Report. Istanbul: Turkey Green Crescent Society. 2011.

10. Petridou E, Moustaki M. Human factors in the causation of road traffic crashes. Eur J Epidemiol. 2000; 16(9): 819-826, indexed in Pubmed: 11297224.

11. Movig KLL, Mathijssen MPM, Nagel PHA, et al. Psychoactive substance use and the risk of motor vehicle accidents. Accid Anal Prev. 2004; 36(4): 631-636, doi: 10.1016/50001-4575(03)00084-8, indexed in Pubmed: 15094417.

12. Elvik R. Risk of road accident associated with the use of drugs: a systematic review and meta-analysis of evidence from epidemiological studies. Accid Anal Prev. 2013; 60: 254-267, doi: 10.1016/j. aap.2012.06.017, indexed in Pubmed: 22785089.

13. CANTÜRK G. Medico-Legal Issues in the Detection of Blood Alcohol. Turkish Clinics, Journal of Forensic Medicine-Special Topics. 2017; 3(2): 125-30.

14. Alcohol, drugs and traffic safety. Accident Analysis \& Prevention. 1982; 14(6): 490-492, doi: 10.1016/0001-4575(82)90070-7.

15. Shih HC, Hu SC, Yang CC, et al. Alcohol intoxication increases morbidity in drivers involved in motor vehicle accidents. Am J Emerg Med. 2003; 21(2): 91-94, doi: 10.1053/ajem.2003.50025, indexed in Pubmed: 12671806.

16. Tien HCN, Tremblay LN, Rizoli SB, et al. Association between alcohol and mortality in patients with severe traumatic head injury. Arch
Surg. 2006; 141(12): 1185-91; discussion 1192, doi: 10.1001/ archsurg.141.12.1185, indexed in Pubmed: 17178960.

17. Orsay EM, Turnbull TL, Dunne M, et al. Prospective study of the effect of safety belts on morbidity and health care costs in motor-vehicle accidents. JAMA. 1988; 260(24): 3598-3603, indexed in Pubmed: 3193590.

18. Lugo LH, García HI, Cano BC, et al. Multicentric study of epidemiological and clinical characteristics of persons injured in motor vehicle accidents in Medellín, Colombia, 2009-2010. Colomb Med (Cali). 2013; 44(2): 100-107, indexed in Pubmed: 24892455.

19. Gotsens M, Marí-Dell'Olmo M, Pérez K, et al. Other MEDEA Members. Trends in socio-economic inequalities in injury mortality among men in small areas of 26 Spanish cities, 1996-2007. Accid Anal Prev. 2013; 51: 120-128, doi: 10.1016/j.aap.2012.10.020, indexed in Pubmed: 23207841.

20. Boström L, Wladis A, Nilsson B. A review of serious injuries and deaths among car occupants after motor vehicle crashes in Sweden from 1987 to 1994. Arch Orthop Trauma Surg. 2001; 121(1-2): 1-6, indexed in Pubmed: 11195103.

21. El-Sadig M, Norman JN, Lloyd OL, et al. Road traffic accidents in the United Arab Emirates: trends of morbidity and mortality during 1977-1998. Accid Anal Prev. 2002; 34(4): 465-476, indexed in Pubmed: 12067109.

22. Sharma BR, Harish D, Sharma V, et al. Road-traffic accidents--a demographic and topographic analysis. Med Sci Law. 2001; 41(3): 266-274, doi: 10.1177/002580240104100311, indexed in Pubmed: 11506352.

23. DeJoy DM. An examination of gender differences in traffic accident risk perception. Accid Anal Prev. 1992; 24(3): 237-246, indexed in Pubmed: 1605809.

24. Buzrul S. Alcohol Consumption in Turkey. Journal of Food and Health Science. 2016: 112-122, doi: 10.3153/jhs16012.

25. Montazeri A. Road-traffic-related mortality in Iran: a descriptive study. Public Health. 2004; 118(2): 110-113, doi: 10.1016/500333506(03)00173-2, indexed in Pubmed: 15037040.

26. Gómez-Restrepo C, Naranjo-Lujan S, Rondón M, et al. Costs of health care and influence of alcohol in traffic accidents in Bogota-Colombia. Journal of clinical epidemiology. 2016.

27. Homma $Y$, Yamauchi S, Mizobe $M$, et al. Emergency department outpatient treatment of alcohol-intoxicated bicyclists increases the cost of medical care in Japan. PLoS One. 2017; 12(3): e0174408, doi: 10.1371/journal.pone.0174408, indexed in Pubmed: 28329002.

28. Kuendig $H$, Hasselberg $M$, Laflamme L, et al. Alcohol and nonlethal injuries: a Swiss emergency department study on the risk relationship between acute alcohol consumption and type of injury. J Trauma. 2008; 65(1): 203-211, doi: 10.1097/TA.0b013e318068fc64, indexed in Pubmed: 18580530.

29. Akay N, Çelik GK, Karakayalı O, et al. The Effects of Blood Alcohol Levels on Injury Severity and Cost in Motor Vehicle Accidents. Ankara Medical Journal. 2014; 14(1).

30. Alp S, Engin T. Analysis and evaluation of the relationship between causes and consequences of traffic accidents by using topsis and ahp methods. Istanbul Ticaret Üniversity, Science Faculty Journal. 2011; 19(10): 65-87. 